In order to achieve maximum effectiveness of a response to a catastrophe, we must, in the future, fill this void by appropriate education and training, rather than the "flying by the seat of our pants", of the past.

The Diploma in the Medical Care of Catastrophes of the Society of Apothecaries in London is a significant attempt to educate and prepare potential disaster responders. This book is the companion text to the diploma. There is a risk with companion volumes in that possibly the "best bits" would be delivered on the course, thereby disabling the book. However, I believe this book is a free standing entity, and I deliberately read and judged it as such, believing that it is valuable to the reader who does not have the opportunity to take the diploma.

Though the topic is large and diverse, the book is an easy read as it is small and contains 29 short chapters. Aspects covered within the book vary from the expected "Medical Response to International Disasters" to the less well acknowledged but vitally important "Post Disaster Assessment of Health Needs" and "Care of Refugees". Many of the things I learned the hard way are delineated in these chapters in a way which will make future responders' lives easier.

The book got better the more I read, which was reassuring, as I felt there was some unnecessary repetition in the earlier chapters. This is mentioned in the preface as being a result of the differing perspectives between civilian and military sources, but I found it rather unnecessary and irritating that similar content was dealt with in different styles. It is mostly a style issue, however, there being no major factual disagreements between the overlapping chapters.

The chapters, written by authors from very different backgrounds, deal largely with the concepts of dealing with the various aspects of response to a catastrophe, with varying amounts of detail in individual chapters. Some issues are dealt with, for example selection of accommodation for medical facilities, in a broad fashion with little detail as to how this might be done in unusual circumstances. Other chapters could almost be used as a planning or packing guide. There is certainly sufficient detail in every chapter to whet the appetite of a newcomer to catastrophe medicine.

Long may the enthusiasm to respond to peoples' distress continue, but, equally well, we must continue to develop responders who are appropriate for the task in hand. This book helps to do just that.

\section{BRENDAN RYAN} Manchester

ECG-Interpretation for Emergency Medicine. A Self Assessment Guide. By Francis Morris, Richard C Jenkins, Javed $M$ Achmed, and David Crossman. (Pp 139; £14.99.) Butterworth-Heinemann, 1997. ISBN 0750630191.

This small volume proves that book reviewing can be enjoyable as well as educational. The preface makes it clear that the aim is very much to complete a practical exercise and that detailed theory is catered for elsewhere. The authors succeed in this aim very successfully to the extent that like a good novel it is very difficult to put this book down once it has been started. My decision to review this book at home rather than as originally intended during a train journey proved wise. My fellow passengers may not have been as tolerant as my wife over my frequent outbursts of delight or disappointment indicating my success, or lack of it, as I progressed through the exercises. The bulk of the book is given over to brief clinical histories and ECG traces followed by the correct interpretation and the relevant learning points. We are informed that all examples are based on factual cases, which adds credibility, and anyone who spends time on the shop floor of the accident and emergency department will identify readily the histories presented. The material should have a wide readership, and while an absolute beginner would be advised to start With ECG Made Easy by Hampton, this is excellent as a follow on or for those of us who have been at it for sometime and are in need of a refresher or a reminder. If I were to make any criticism it would be that the section on rhythm strips appears to have been tacked on as an afterthought and I feel would have been better presented in the same format as the other exercises within the book.

I do not believe that there is any doctor (or nurse) involved in acute specialties who would not gain from spending an evening with this book or get a significant degree of enjoyment from the experience. One puzzle remains, why is the ECG trace on the front cover upside down?

WILLIAM G MORRISON Dundee

\section{Correction}

In the January issue of the journal ( $\mathcal{F}$ Accid Emerg Med 1999;16:64) Michael Cook should have read Matthew Cooke. We apologise for this error. 